\title{
Analysis and Disposal for Vibration of Vertical Circulating Water Pump
}

\author{
Han Lizheng \\ Department of Vessel and Machinery, China Chengda Engineering Co., Ltd, Chengdu, China
}

Email address:

hanlizheng@chengda.com

\section{To cite this article:}

Han Lizheng. Analysis and Disposal for Vibration of Vertical Circulating Water Pump. American Journal of Mechanical and Industrial Engineering. Vol. 3, No. 3, 2018, pp. 34-38. doi: 10.11648/j.ajmie.20180303.11

Received: May 24, 2018; Accepted: June 27, 2018; Published: July 25, 2018

\begin{abstract}
Based on the vibration of circulating water pump in a coal-firing power plant phase II in Indonesia, analysis had been carried out from different aspects for the problem. The key factors concluded were insufficient taper plates and unqualified secondary grouting. Meanwhile, single foundation, high structure above the foundation, higher speed than normal and insufficient structural stiffness were formed the influence factors, which led to the undesirable disposal results. The vibration of 3B was still exceeding $4.5 \mathrm{~mm} / \mathrm{s}$ specified by the standard, $3 \mathrm{~A}$ was just meeting the value, and the vibration of $4 \mathrm{~A}, 4 \mathrm{~B}$ was $2.8 \mathrm{~mm} / \mathrm{s}$. The advice and suggestion had been summarized.
\end{abstract}

Keywords: Vertical Circulating Water Pump, Vibration, Analysis, Disposal, Taper Plates, Secondary Grouting, Insufficient Structural Stiffness

\section{Introduction}

There were two vertical circulating water pumps for a $65 \mathrm{MW}$ coal-firing power plant phase II in Indonesia, numbered: $3 \mathrm{~A}$ 、 3B、4A、4B. The circulating water was a monobloc configured system, and two circulating water pumps run in parallel under rated condition. During the commissioning, the vibration (refers to the radial vibration, hereinafter the same) of $3 \mathrm{~B}$ was very high in the first mechanical running. 3A ran normally in the first 2 hours, and then the vibration increased suddenly until exceeding the specified value.

The circulating water pump was mix-flow type, single foundation, discharge above foundation, shaft thrust endured by thrust bearing in pump side (Figure 1).
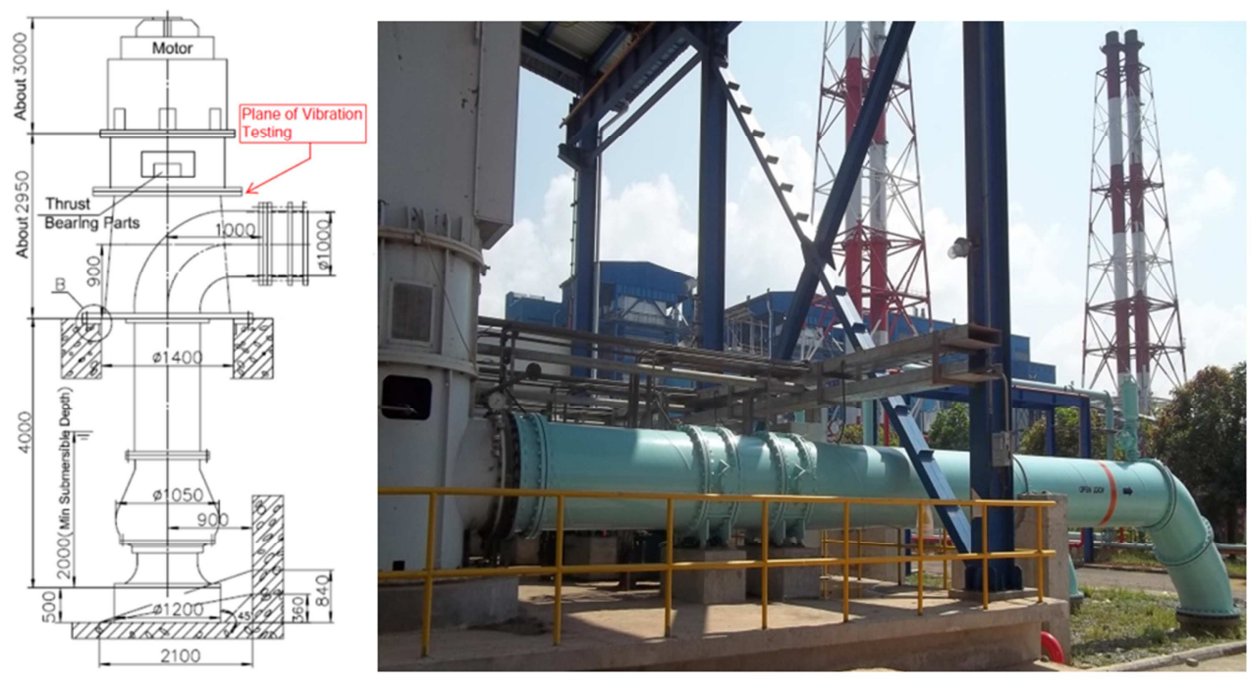

Figure 1. Circulating water pump arrangement drawing and discharge piping system of phase II. 
Table 1. Performance parameters of circulating water pump.

\begin{tabular}{llllllll}
\hline Flow $\mathbf{m} 3 / \mathbf{h}$ & Head $\mathbf{m}$ & Speed rpm & Efficiency $\%$ & NPSHr m & Shaft power kW & Motor kW & Max. shaft thrust ton \\
\hline 7100 & 24.5 & 740 & 86.2 & 7.54 & 572 & 710 \\
\hline
\end{tabular}

\section{Method}

In most cases, the affecting factors of vibration are complex instead of single one, such as: levelness, alignment, cavitation, poor condition of water intake, air lock of discharge piping system and manufacturing, etc. During the mechanical running of $3 \mathrm{~A}, 3 \mathrm{~B}$, the water level in intake pool was normal and no noise came out from pumps, both the discharge pressure and motor current were steady. So, the cavitation and air lock of discharge piping system could be excluded $[1,2]$.

The vibration of circulating water pump should be analyzed from other aspects and tried to find out the disposal.

\subsection{Levelness and Alignment}

Levelness and alignment are always the prior factors for solving vibration problem, and also the easier ones than the other factors for carrying out. In fact, levelness affected the vibration obviously during motor solo running of $3 \mathrm{~B}$ and $3 \mathrm{~A}$. According to the first time motor solo running records in Aug. 2011, vibration value of $3 \mathrm{~B}$ motor was $3.1 \mathrm{~mm} / \mathrm{s}$ and $3 \mathrm{~A}$ motor $1.8 \mathrm{~mm} / \mathrm{s}$ (testing point: motor NDE) while the levelness of $3 \mathrm{~B}$ and $3 \mathrm{~A}$ were $0.40 \mathrm{~mm} / \mathrm{m}$ and $0.90 \mathrm{~mm} / \mathrm{m}$, which were far exceeding $0.05 \mathrm{~mm} / \mathrm{m}$ specified by the pump manufacturer. During the first mechanical running of $3 \mathrm{~B}$, the vibration value reached $8.0 \mathrm{~mm} / \mathrm{s}$ (vibration testing point at flange plane near thrust bearing referred to Figure 1, same below for mechanical running), which was evaluated unacceptable according to reference [3].

When the leveling through stainless shims was complete, the vibration value of $3 \mathrm{~B}$ was reduced to $6.5 \mathrm{~mm} / \mathrm{s}$ in the mechanical running, which meant that leveling was one of major influencing factors.

Alignment was not the major factor for $3 \mathrm{~B}$, because it was always in a good condition during each checking while the vibration was high.

\subsection{Modification of Discharge Piping System}

There was a closed relationship between the vibration and the extra force and torque set on pump by discharge piping system [4]. The discharge pipe of circulating water pump was above foundation, and the stress from piping system would set influence on levelness and alignment leading to vibration [5, 6]. The total length of 3B discharge piping above foundation was $9.51 \mathrm{~m}$, the top-bottom offset was $64 \mathrm{~mm}$ and left-right offset was $17 \mathrm{~mm}$, which illustrated that the piping system had already set stress on the pump. Then, the modification of $3 \mathrm{~B}$ discharge piping system was carried out in order to eliminate the stress. Detail method was adjusting each flange connection from pump discharge to underground pipe (Figure 2). There should be no extra torque set on flanges during tightening the bolts, which could be confirmed from the dial gauge set on the flanges.

When the modification of discharge piping system was complete, the vibration value of $3 \mathrm{~B}$ was reduced to $6.2 \mathrm{~mm} / \mathrm{s}$ in mechanical running, which meant the stress caused by offset would affect the vibration, even it was not the major impacting factor.

Besides, the length between circulating water pump discharge flange and hydraulic butterfly valve was $2 \mathrm{~m}$, and the nominal diameter was DN1100. The pipe was restricted by pump body and the support of hydraulic butterfly valve, which meant that the pipe would set extra force and torque on pump. Comparing to phase I, the length between circulating water pump discharge flange and hydraulic butterfly valve was no more than $1.5 \mathrm{~m}$, and there was another support near flexible joint. The restriction of circulating water pump discharge piping system of phase I was similar with "wall pipe" which was normally applied to the circulating water pump with discharge under foundation. The radial and axial restriction of wall pipe was better than phase II. So, under the dynamic condition, whether the extra force and torque generated by both water flow and discharge piping system of phase II would cause vibration, some more research and experiment should be necessarily needed.

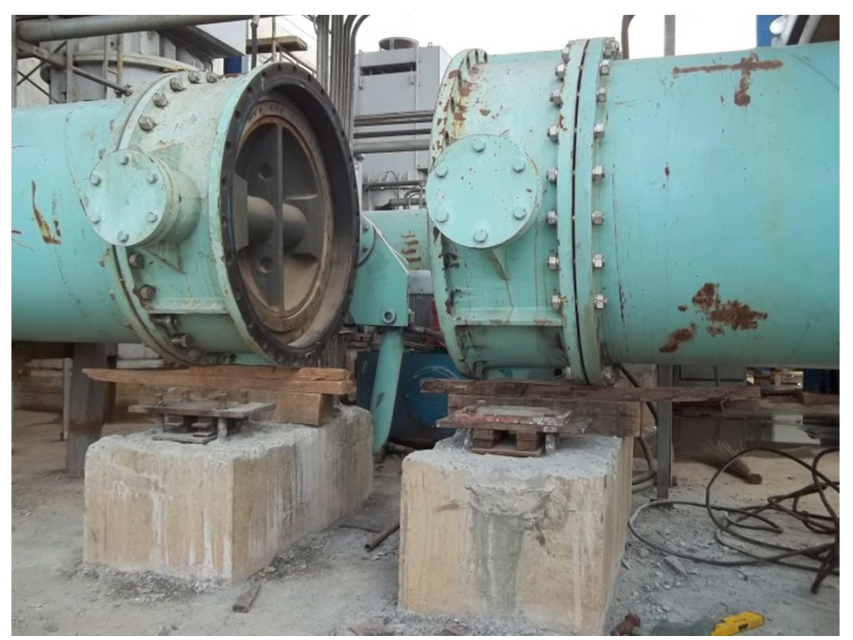

Figure 2. Modification of $3 B C W$ pump discharge piping system.

\subsection{Foundation Modification}

One anchor bolt was drawn out during the leveling and commissioning of $3 \mathrm{~B}$, because the anchor bolts had been tightened and loosened repeatedly. The anchor bolt was up $25 \mathrm{~mm}$ (Figure 3 ) and the others were checked one by one and most of them were drawn out with different lifting length. Secondary grouting was found unqualified when foundation was cracked, including: secondary grouting was divided into two periods while it should be continuous, the two grouting layers were well-defined and there were much sundries, dust and sand between the two layers, which should be cleared up 
before grouting. Most of anchor bolt holes were still half empty and filled with support materials while the secondary grouting had been completed. That was why the anchor bolts could not be fixed firmly.

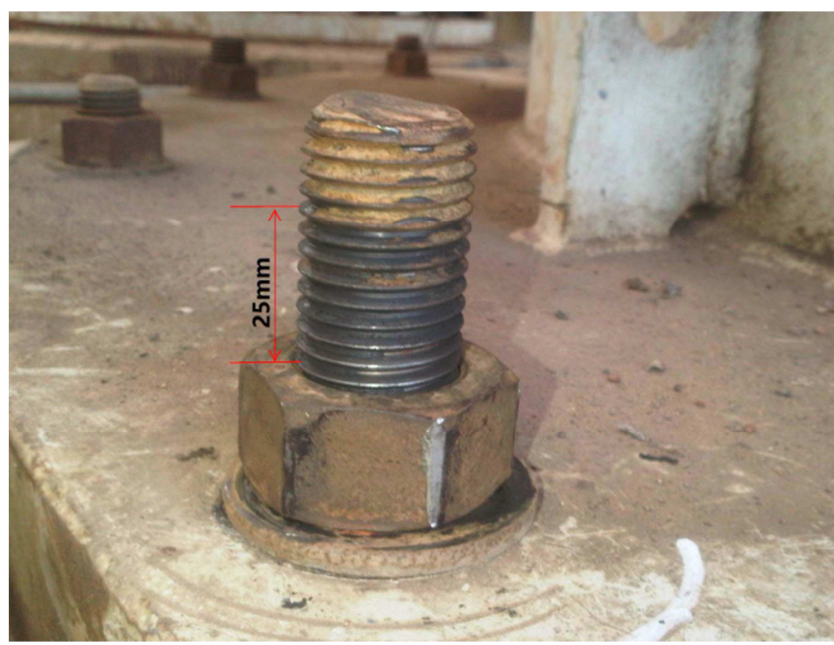

Figure 3. One anchor bolt of $3 B$ drawn out.

Besides, the taper plates set under leveling plate were not enough. According to the Installation Manual of Circulating Water Pump [11], there should be 32 sets taper plates for each circulating water pump. However, only 8 sets were installed actually in situ. That the surface of $3 \mathrm{~B}$ leveling plate was found irregular measured through level meter before cracking the foundation, should be closely related with the insufficient taper plates, unqualified secondary grouting and repeated mechanical running.

All foundations of 4 circulating water pumps were cracked and reset 32 sets taper plates under leveling plate. The anchor bolts were spot welded with steel bars embedded in the foundation in order to fix them firmly (Figure 4).

When the modification of foundation was complete, the vibration values of $3 \mathrm{~A}, 3 \mathrm{~B}$ were $4.3 \mathrm{~mm} / \mathrm{s}$ and $4.8 \mathrm{~mm} / \mathrm{s}$, which could prove that insufficient taper plates was another major influence factor of vibration.

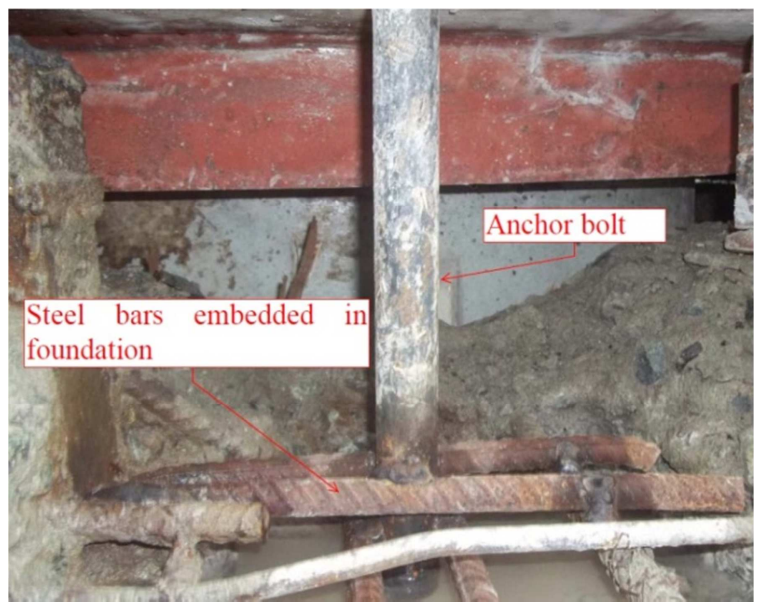

Figure 4. Anchor bolt was spot welded with steel bars embedded in foundation.

\section{Result}

Although the vibration had been reduced by a big margin through leveling, alignment, modification of discharge piping system, resetting taper plates and grouting, $3 \mathrm{~A}$ could just meet Class C [3] $(4.5 \mathrm{~mm} / \mathrm{s})$ and $3 \mathrm{~B}$ met Class $\mathrm{D}$ which meant vibration would cause damage, $4 \mathrm{~A}$ and $4 \mathrm{~B}$ could meet Class $\mathrm{B}$ $(2.8 \mathrm{~mm} / \mathrm{s})$. The vibration of $3 \mathrm{~B}$ was worse than the other three pumps and $3 \mathrm{~A}$ was worse than $4 \mathrm{~A}, 4 \mathrm{~B}$, which were related to the repeated mechanical running before resetting taper plates and modification of foundation. The leveling plate of $3 \mathrm{~B}$ had been plastic deformation, and the sliding bearings had been worn unevenly, which would lead to high vibration during the pump running. Basis on Table 2, while the pump ran continuously, the vibration of $3 \mathrm{~B}$ was increasing gradually. The sliding bearings needed to be checked and changed during the maintenance [7]. While the mechanical running of $4 \mathrm{~A}, 4 \mathrm{~B}$ started, resetting taper plates and modification of foundation had been already complete. So, the leveling plates and sliding bearings of 4A, 4B were harmed a little.

The $3 \mathrm{~B}$ vibration values of different stage were listed in Table 2:

Table 2. 3B vibration values of different stage unit: $\mathrm{mm} / \mathrm{s}$.

\begin{tabular}{|c|c|c|c|c|}
\hline first mechanical running & re-leveling & modification of discharge piping & resetting taper plates and grouting & after 5 months running \\
\hline 8.0 & 6.5 & 6.2 & 4.8 & 5.2 \\
\hline
\end{tabular}

\section{Discussion}

According to reference $[6,8]$, the structural stiffness of circulating water pumps was insufficient, both displacement and deformation occurred under the external force, which would change the alignment and cause vibration increasing. Such as the discharge piping system arrangement of phase II, even the structural stiffness was sufficient in the static conditions, once circulating water pump started, there was also the risk that the extra dynamic load from water flow would pull and push the pump body through pipeline, which would lead to high vibration. So, it was necessary to simulate the dynamic condition and recheck the structural stiffness.

Although $4 \mathrm{~A}$ and $4 \mathrm{~B}$ was running in a good condition, shaking could be felt from the pump outer casing and the shaking from motor NDE was especially obvious. The shaking should be related to the following aspects:

(1) Circulating water pumps of phase II were single foundation, both pump and motor loaded on the leveling plate. The thrust bearing was set on pump side, which caused the height above foundation much higher than the ones with thrust bearing on motor side. The total height above foundation of phase II was $5.9 \mathrm{~m}$. The vibration of circulating water pumps in reference [9] was high and shaking because of the unsubstantial outer casing and insufficient structural stiffness, 
which was similar with phase II. The solution given in the reference was increasing the thickness of supporting structure, e.g., the thickness of outer casing increased from $10 \mathrm{~mm}$ to $18 \mathrm{~mm}$. The parameters of circulating water pumps of phase I were listed in Table 3. They were also single foundation, but the thrust bearing was on motor side and the height above foundation was much smaller than phase II. The pump and motor was lighter than phase II, while the thickness of mounting plate was much thick than phase II (Figure 5).

Table 3. Comparing of circulating water pump in phase II and I.

\begin{tabular}{|c|c|c|c|c|c|c|c|}
\hline item & foundation & $\begin{array}{l}\text { thrust bearing } \\
\text { location }\end{array}$ & $\begin{array}{l}\text { height above } \\
\text { foundation } \mathbf{m}\end{array}$ & $\begin{array}{l}\text { Weight pump/motor } \\
\text { ton }\end{array}$ & $\begin{array}{l}\text { thickness of outer } \\
\text { casing } \mathrm{mm}\end{array}$ & $\begin{array}{l}\text { thickness of } \\
\text { mounting plate } \mathbf{m}\end{array}$ & $\begin{array}{l}\text { vibration value } \\
\mathrm{mm} / \mathrm{s}\end{array}$ \\
\hline Phase II & single & pump & 5.9 & $16 / 7.5$ & 11 & 11 & $2.8 \sim 4.8$ \\
\hline Phase I & single & motor & 3.5 & $11 / 6.5$ & 11 & 18 & 1.5 \\
\hline
\end{tabular}

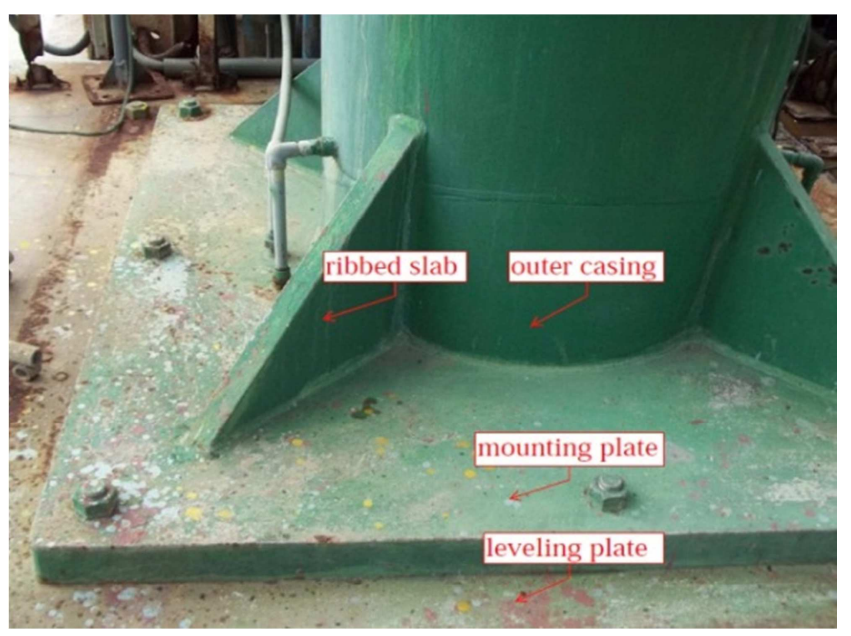

Figure 5. Outer casing and mounting plate of circulating water pump in phase $I$.

(2) According to the reference submitted by the supplier of circulating pump of phase II, the speed of pump was 590rpm, $375 \mathrm{rpm}$ or even lower, while 740rpm was a new type and it was also rare in other pump suppliers with the similar parameters during that years. Basis on the writer's subsequent investigation, there was other cases of vibration problems because of high speed, which was same with speed and pump supplier of phase II [10]. Once the structural stiffness of supporting structure was insufficient, high speed would lead the vibration to a worse condition undoubtedly. In order to win the bidding, reduction of cost is always the preferred business strategy. High speed could reduce the cost, while the pump could not run in a good condition because of the vibration caused by multiple influence factors, and the performance life of equipment would also be influenced in a large part.

\section{Conclusion}

Insufficient taper plates and unqualified secondary grouting were the major influence factors for vibration of phase II. According to the difference of vibration values, leveling was another influence factor and the vibration of circulating water pump in phase II was influenced by alignment a little. So, key control points should be highly supervised during the installation of vertical type circulating water pump. Unqualified installation would lead to reworking and delayed schedule. Since the vibration problem had already been found during the first running, analysis should be taken at once instead of persisting to let the pump running under high vibration with fluke mind, which would make the problem get worse. Whether the extra force and torque generated by both water flow and discharge piping system would cause vibration and what was the influence degree, some more research and experiment should be necessary. All circulating water pumps of phase II were shaking during the mechanical running, which resulted in the combination of single foundation, big dimension above foundation and high speed. The combination should be avoided in the engineering. Or else, the structural stiffness must be simulated and calculated meticulously under static and dynamic conditions to make sure sufficient structural stiffness. The vibration of $3 \mathrm{~A}$ increased suddenly during the first mechanical running resulted in the changes inside foundation caused by the unqualified secondary grouting and less taper plates.

\section{References}

[1] WANG Wei. Analyzing and Improvement of Cavitation for Circulating Water Pump in Chemical Industry [J]. Energy Conservation in Petroleum \& Petrochemical Industry, 2017, 7(8): 24-27.

[2] JIAO Hongrui, LIANG Yaxun. Analyzing and Solution of Vibration for Circulating Water Pump in Nuclear Power Station [J]. Pump Technology, 2016(3): 42-46.

[3] ISO10816-3: Mechanical Vibration-Evaluation of Machine Vibration by Measurements on Nonrotating Parts, Part 3: Industrial Machines with Nominal Power above $15 \mathrm{~kW}$ and Nominal Speeds between $120 \mathrm{r} / \mathrm{min}$ and $15000 \mathrm{r} / \mathrm{min}$ when Measured in Situ [S].

[4] ZHOU Jing, DUAN Xueyou. Analysis of Heat Supply Network Circulation Pump Vibration in 350 MW Supercritical Unit and Its Disposal [J]. Inner Mongolia Electric Power, 2017, 35(4): 81-83.

[5] HOU Zhenyu, QU Shidong. Analysis and Solutions for Vibration of Circulating Water Pump [J]. Chemical Engineering \& Machinery, 2010(5): 666 667.

[6] LI Jun, WANG Yanshan. The Fault Analysis of the Vertical Circulating Pump's Strong Vibration [J]. Shanxi Electric Power, 2014(2): 63 66.

[7] JU Lietao, TAO Shai. Reduce 88LKXA-20 Circulating Water Pump Vibration Analysis and Application [J]. Jiangxi Energy, 2015(4): 65-69. 
[8] ZHU Cheng. Analysis and Solutions for Vibration of Circulating Water Pump in Coal-fired Power Plant [J]. China New Technologies and Products, 2013, NO. 08: 108 109.

[9] WANG Lu. Analysis and Solutions for Abnormal Vibration of Circulating Water Pump [J]. Huadian Technology, 2012, 34(5): 56-59.

[10] WANG Sheng'en, ZHAO Guoquan, ZHU Jianhua. Solutions Discussion for Vibration of 48LKXB232 Type Circulating Water Pump [J]. China Science and Technology Review, 2009(3): 6-6.

[11] HUNAN XEMC CHANGSHA PUMP WORKS CO., LTD. Installation Manual of Circulating Water Pump [Z].

\section{Biography}

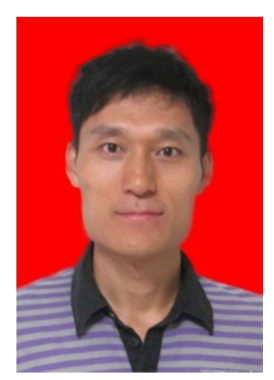

Han Lizheng (1981-), Male, the place of origin is Yutian County, Hebei Province, China, Senior Engineer, Graduate Student for A Master's Degree, Major in Research of Fluid Machines and Motive Power Machines, such as Pumps with Different Type, Fans \& Blowers, Compressors with Different Type, Steam turbines and Gas turbine, etc. Address: NO. 279, Middle Section, Tianfu Avenue, Chengdu, Sichuan, China. 